temporal quadrant. In another case vision was poor and both optic discs were pale; contraction of the fields of vision.

We note that pathological material supplied by members of the Society will be reported upon free by the Society. The Bulletin gives directions how to collect and prepare specimens for examination.

S.S.

Précis d'Ophtalmologie. By Dr. V. Morax, Ophtalmologist de l'hôspital Lariboisière. Troisième édition refondue, Paris. Masson et Cie, 120, Boulevard St. Germain. 1922.

Although the third edition of Dr. Morax's excellent Précis d'Ophtalmologie bears the date 1921 it did not reach us until the present year was well advanced. Hence the delay in the appearance of this notice. It may be said, however, that it is one of the best of the smaller text-books of ophthalmology. There is but one criticism to make, namely, that many of the black and white illustrations are deplorably inartistic and unworthy of the book.

S. S.

\title{
CORRESPONDENCE
}

\section{PROFESSOR VOGT'S COURSE OF MICROSCOPY OF THE LIVING EYE AT BASEL}

To the Editor of The British Journal of Ophthalmology

SiR,--We have been interested for some time in microscopy of the living eye, and on learning from an advertisement in the Continental ophthalmic journals that Professor Vogt, of Basel, was proposing to hold a course in Spaltlampenmikroskopie during the first week of September we arranged to attend. The course took place in the University Eye Clinic and lasted for six days, there being lecture demonstrations for four to five hours daily. About thirty oculists attended, twelve countries being represented, and the teaching, as is usual on the Continent, was very practical in character.

Professor Vogt had at his disposal about a dozen Zeiss corneal microscopes with the Gullstrand slit-lamp illumination, and dealt very fully with the microscopy of the cornea, iris, lens and vitreous in both normal and pathological cases. We cannot praise too highly the careful and efficient manner in which he and his staff of demonstrators conducted the course. No efforts were spared to enable each individual attending to overcome the technical difficulties of the instrument, and a very large-number of cases of 
great clinical interest were provided for examination. The sum of thirty francs to cover expenses was asked, but no fee. Should Professor Vogt hold a similar course next year, any British ophthalmologist who wishes to attend may be assured of a hearty welcome in Basel and a most interesting and profitable week of instruction.

Yours truly,

EDinbergh.

James V. Paterson, E. H. Chimeron.

\section{BUTYN-A SUBSTITUTE FOR COCAIN}

\section{To the Editor of ThE British Journal of OphThalmology}

SIR,-My attention was directed to butyn by Mr. W. M. Beaumont, of Bath, who kindly sent me a small quantity of a 2 per cent. solution for trial.

This was sufficient for 15 operations, viz. : 1 Optical iridectomy, 1 discission, 1 expression of the lens in its capsule, 1 tattooing of the cornea, and the remainder cataract extraction with conjunctival flap and late iridectomy.

The drug was used as recommended, i.e., 4 instillations of a 2 per cent. solution at intervals of 3 minutes.

In the early cases the speculum was removed before performing the iridectomy, but as the grasping and cutting of the iris appeared to be painless, in the later operations the speculum, although controlled by an assistant, was safely left until the end of the operation.

The claim that anaesthesia is more profound than with cocain would therefore appear to be justified.

The mild hyperaemia of the conjunctiva was in no way troublesome, and the bleeding from the conjunctival flap was not appreciably increased.

The absence of mydriasis and desiccation of the cornea was noteworthy, and there were no post-operative complications of any kind.

This very limited experience has been so satisfactory that it is recorded in the hope that butyn may become extensively used by ophthalmic surgeons in India, where the illicit use of cocain has reached serious dimensions. Smugglers of the drug have become so numerous and so daring that they recently enticed a band of Calcutta Police to personal combat on the river.

The value of an efficient substitute for cocain which is harmless from the social point of view cannot be overestimated, and its use is in the nature of a moral obligation. 